\title{
Accessibility to, Acceptability of, and Adherence to HIV/AIDS Prevention Services by Men Who Have Sex with Men: Challenges Encountered at Facility Level
}

\author{
P. C. N. Otambo, ${ }^{1}$ A. Makokha, ${ }^{2}$ M. Karama, $^{1}$ and M. Mwangi ${ }^{1}$ \\ ${ }^{1}$ Kenya Medical Research Institute, P.O. Box 54840, Nairobi 00200, Kenya \\ ${ }^{2}$ Jomo Kenyatta University of Agriculture and Technology, P.O. Box 62000, Nairobi 00200, Kenya \\ Correspondence should be addressed to P. C. N. Otambo; priotambo@gmail.com
}

Received 21 January 2016; Revised 3 May 2016; Accepted 31 May 2016

Academic Editor: Julio Diaz

Copyright ( 92016 P. C. N. Otambo et al. This is an open access article distributed under the Creative Commons Attribution License, which permits unrestricted use, distribution, and reproduction in any medium, provided the original work is properly cited.

The prevalence of HIV/AIDS among men who have sex with men (MSM) in Nairobi has been reported to be $16.4 \%$ which is a public health concern. The aim of this study was to determine factors that affected accessibility to, acceptability of, and adherence to HIV/AIDS prevention services by men who have sex with men in Nairobi County, Kenya. Methods. The study used a mixed methods design, applying both quantitative and qualitative methods. Results. Over 70\% of MSM reported that TB drugs, antiretroviral drugs, lubricants, condoms, and other STI treatment services were accessible. However, 31.6\% of MSM reported that discrimination at the health facility level was a hindrance to accessing HIV/AIDS prevention services while $26.3 \%$ reported encountering stigma. $48.4 \%$ of MSM consumed alcohol while taking of drugs was reported, at $36.1 \%$. Conclusion. Discrimination and stigma adversely affected MSM seeking HIV/AIDS prevention services in health facilities. MSM engaged in alcohol and substance abuse that likely affected their health seeking behavior. Although most prevention services are reported as accessible, uptake of the same needs to be considered.

\section{Background}

Gay populations have a higher risk of HIV infection in every region of the world. Globally, gay men and other men who have sex with men are 19 times more likely to be living with HIV than the general population [1]. In African context, the prevalence rates of HIV/AIDS among MSM are significantly higher than the national HIV prevalence rates and this is evidenced by studies that have been carried out in Mombasa, Kenya [2]; Nairobi, Kenya (18.2\%) [3]; Blantyre and Lilongwe, Malawi (21.4\%) [4]; Dakar, Senegal (21.8\%) [5]; and Cote d'Ivoire (50.0\%) [6]. The HIV epidemic in Kenya has evolved since the first case was diagnosed in 1984, to become one of the major causes of mortality, and it has placed tremendous demands on the health system and the economy. Many MSM in Africa engage in sexual activities with women and many are also married to or are in a long-term relationship with a woman [7]. Although condom use has been reported to be as high as $86 \%$ [8] among some MSM populations, other studies have reported the utilization of condoms to be as low as 32\% [9] and, in many cases, they are often used incorrectly [10]. Many MSM have also been reported to engage in multiple concurrent sexual relationships and transactional sex [11]. Regular substance abuse, particularly alcohol abuse, has also been found to be quite common in MSM populations, increasing the risk of HIV infection [12]. The prevalence of other STIs has been found to be significantly higher among the MSM population, compared to the general male population [13]. Structural barriers at the policy, cultural, and institutional level which include criminalization of homosexuality, high levels of stigma and discrimination, and homophobia in healthcare systems have been documented [1]. This contributes to fear among MSM in revealing their sexual behavior to healthcare providers, resulting in increased risk of misdiagnosis, delayed diagnosis, and delayed treatment and therefore running a higher risk of transmitting HIV and other sexually transmitted infections to partners. In Kenya, HIV/AIDS prevention strategies 


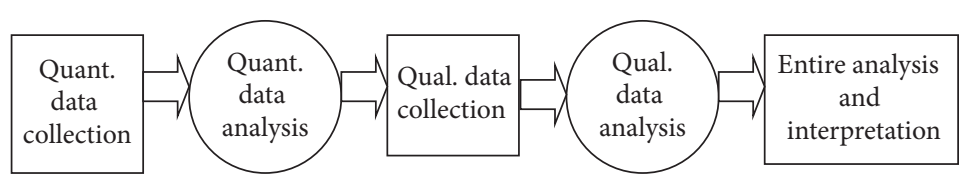

Quant.: quantitative

Qual.: qualitative

FIgURE 1: Sequential explanatory mixed methods design.

have been in existence for several years now; however, the prevalence of HIV and AIDS among MSM in Nairobi is relatively high, reported to be $16.4 \%$. This study explored and determined factors affecting accessibility to, acceptability of, and adherence to HIV/AIDS prevention services among men who have sex with men in Nairobi County.

\section{Methodology}

2.1. The Study Site. The study was based in Nairobi County, which is one of the 47 counties of Kenya. Nairobi city is also the capital city of Kenya. It has a population of about four million. Nairobi is divided into seventeen constituencies and eighty-five wards. The county has three level 4 health facilities, one referral hospital, four major private hospitals, and numerous health dispensaries both public and private. The study site was chosen based on the presence of gay communities, including MSM. The relatively high prevalence of HIV/AIDS among the MSM is of public health concern.

2.2. Study Design. This study employed a sequential explanatory mixed methods design [14] as shown in Figure 1 that involved both qualitative and quantitative data collection and analysis techniques. This approach provides more insights into the quantitative study by exploring participant's views in more depth to fully answer the objective of the study $[14,15]$. The two phases of the research were integrated in the findings.

2.3. Study Population. The quantitative study population comprised MSM residing in Nairobi. Inclusion criteria were as follows: born male, 18 years of age or older, reporting ever having oral or anal sex with another man, and willing to participate in the study. The qualitative study population included key informants who were in charge of HIV/AIDS programmes in purposely selected public and private health facilities and in charge of nongovernmental organizations that offered HIV/AIDS health support services to MSM.

2.4. Study Setting. The study was carried out from June 2014 to March 2015. Quantitative data was collected using selfadministered questionnaires and it targeted MSM. The tool for quantitative data collection was pretested with a group of MSM in a nongovernmental organization that offered HIV/AIDS health support services. The tool was translated into the national language (Kiswahili) for ease of communication. After pretesting, the tool was then reorganized to address any deficiencies that had been observed. Research assistants for data collection in this phase were MSM who were trained and who utilized snowballing technique to identify subsequent respondents in their networks. The goal of this first phase was to get the general statistics on accessibility to HIV/AIDS prevention services by MSM. Preliminary data analysis was then carried out after which a tool for qualitative data was designed based on the outcomes of the quantitative findings. The qualitative study targeted MSM as well as the programme managers in charge of HIV/IDS prevention services in purposely selected public and private health facilities and directors in charge of nongovernmental organizations that offered health support services to MSM.

2.5. Recruitment. Recruitment for quantitative data was done using snowballing and targeted the MSM. Six MSM were purposely selected and requested to be the research assistants. Upon consent, they were trained. They were then involved in the recruitment of other MSM respondents in their various networks. A total of $380 \mathrm{MSM}$ were reached within one month. The initial calculated minimum sample size was 200 MSM. For qualitative study, in-depth interviews were conducted with key informants who were programme managers in charge of six purposely selected public and private health facilities and also those in charge of three nongovernmental organizations that offered HIV/AIDS health support services to MSM. For the four focus group discussions that were conducted with MSM, three groups comprising a minimum of 10 participants each were randomly drawn from three purposely selected nongovernmental organizations that offered HIV/AIDS health support services to MSM using the telephone number register owned by each organization. The fourth group comprised MSM that had participated in the quantitative phase.

2.6. Data Collection. A developed self-administered questionnaire was used to collect the data for quantitative study. The data collected included accessibility to condoms, lubricants, HIVAIDS counseling services, HIV/AIDS treatment services, and health facilities. For FGDs, four focus group discussions were conducted among MSM that contained between 10 and 14 participants in each group using a developed guide. They were conducted in excluded areas of their choice for their own psychological and physical safety concerns. The FGDs were moderated by an expert in qualitative studies who was assisted by three trained qualitative research assistants who took notes verbatim and tape recordings. The discussions were conducted on a round table after consent to participate in the study was sought. Questions explored what experiences MSM had faced when accessing HIV/AIDS care 
and treatment services in public and private health facilities, whether the HIV/AIDS treatment and care services were user friendly, what needed to be done in order for their own health needs to be met within the healthcare system, what worked for them in terms of accessibility towards HIV/AIDS intervention programmes, and what barriers the MSM had encountered, prior to this study, in seeking healthcare from Nairobi County public healthcare facilities. Also included in the qualitative phase were nine key informant in-depth interviews conducted with managers in charge of HIV/AIDS programmes in public health facilities and nongovernmental organizations that offered healthcare support services to MSM. The in-depth interviews were carried out in the offices of the relevant organizations. They were moderated by two researchers that were responsible for visiting the selected organizations, developing a rapport with relevant officers to be interviewed, seeking consent, and carrying out the interviews. The interviews covered challenges encountered when offering healthcare services to MSM, the attitude of MSM towards HIV/AIDS prevention services, treatment and care offered, how the services could be improved, whether the MSM adhered to the service requirements, and the challenges involved in offering these services to MSM.

2.7. Data Analysis. Data analysis for quantitative study was done using SPSS statistical software (Ver. 20). Data was kept under lock and only accessed by authorized personnel. Qualitative analysis was carried out using the six stages of the Framework Method [16]. Interviews were transcribed verbatim; and those conducted in Kiswahili (Kenya's national language) were back translated into English. This data was then explored to identify important and relevant themes of the study. These were subsequently labeled according to their relevance and a series of categories built up to explain the events that were emerging from the study. This data was categorized manually into themes around the core issues relating to accessibility to, acceptability of, and adherence to HIV/AIDS prevention services by MSM and any challenges encountered at facility level. Emerging categories were merged to form core categories which are discussed in this paper. This exercise was carried out by qualitative data collection personnel supervised by an expert in qualitative analysis who was also part of the study.

\section{Ethical Approval}

Ethical approval to conduct this study was sought from the Kenya Medical Research Institute (KEMRI) Scientific and Ethical Review Unit (SERU) under SSC protocol number 2612 of 31/3/2014 as well as written permission from the County Director of Health. Appointments were made with the managers in charge of public and private health facilities and those of the nongovernmental organizations included in the study to explain the purpose of the study after which consent from them was obtained to carry out interviews. Signed informed consent was also obtained from the MSM both for quantitative and for qualitative participation. Participation was fully voluntary and confidentiality was observed at all times.

\section{Findings}

\subsection{Quantitative Findings}

4.1.1. Sociodemographic and Behavioral Characteristics of MSM. A total of 380 MSM aged 18 years and above were asked to be part of the study and 380 (100\%) consented. Sociodemographic and behavioral attributes of the study participants are as shown in Table 1. The majority of the respondents (86.4\%) were aged between 18 and 34 years. About one-third of the respondents (31.6\%) were aged between 20 and 24 years while $6.6 \%$ were 40 years old and above. About two-thirds of the respondents (62.9\%) had university or college level of education. About half of them (52.6\%) were not married. Protestant followers accounted for the highest percentage in religion $(38.2 \%)$. With respect to occupation, sex work was indicated as the highest percentage (26.2\%) followed by salaried employee $(25.0 \%)$. Almost half (48.8\%) of the respondents had taken alcohol once a week in the previous one month before the study while $12.6 \%$ had never taken alcohol. The use of drugs was reported by majority of respondents with the highest percentage having used bhang $(36.1 \%)$.

4.1.2. Accessibility to HIV/AIDS Prevention Services by MSM. Majority $(84.5 \%)$ of the respondents indicated that condoms were accessible when needed and $70.1 \%$ revealed that circumcision services were available in the area of residence (Table 2). Most respondents reported that they had access to TB drugs (70.5\%), antiretroviral drugs (71.6\%), lubricants (79.5\%), IEC materials on HIV/AIDS prevention (70.8\%), training in HIV/AIDS prevention (68.7\%), health facilities when required $(72.1 \%)$, and STIs treatment $(76.8 \%)$.

4.1.3. Counseling among Those Who Had Undertaken HIV/AIDS Test prior to the Study. About half (52.8\%) of the respondents who had undertaken HIV test prior to this study reported that they got pretest and posttest counseling while $11.0 \%$ got only pretest counseling, $6.9 \%$ got only posttest counseling, and $3.6 \%$ had no counseling as depicted in Figure 2. A quarter of the respondents declined to answer the question on counseling aspect.

4.1.4. Personal Experiences as Reported by the MSM. Personal experiences in their daily interaction as MSM were measured using five variables as shown in Figure 3. This measure was important because it was assumed that it could have affected acceptability of HIV/AIDS prevention services mostly at facility level. Thereafter, more exploration was done in the qualitative study. In their day-to-day interaction, the MSM reported what they had mostly experienced as MSM prior to this study. They reported that they had faced discrimination $(38.2 \%)$ followed by stigma (17.6\%), and rejection was reported by $8.7 \%$. There are those who reported that they had routinely experienced all the five variables (26.6\%).

4.2. Qualitative Findings. To have an in-depth understanding of the quantitative results, qualitative research was incorporated in this study. Findings reported here are on themes 
TABLE 1: Sociodemographic and behavioral characteristics of MSM.

\begin{tabular}{|c|c|c|}
\hline Variables & $n=380$ & $\%$ \\
\hline \multicolumn{3}{|l|}{ Age of the respondent in years } \\
\hline$<20$ & 30 & 7.9 \\
\hline $20-24$ & 120 & 31.6 \\
\hline $25-29$ & 107 & 28.2 \\
\hline $30-34$ & 71 & 18.7 \\
\hline $35-39$ & 27 & 7.1 \\
\hline $40+$ & 25 & 6.6 \\
\hline \multicolumn{3}{|l|}{ Level of education } \\
\hline None & 11 & 2.9 \\
\hline Primary & 26 & 6.8 \\
\hline Secondary & 104 & 27.4 \\
\hline College & 127 & 33.4 \\
\hline University & 112 & 29.5 \\
\hline \multicolumn{3}{|l|}{ Religion of the respondent } \\
\hline Protestant & 145 & 38.2 \\
\hline Catholic & 128 & 33.7 \\
\hline Muslim & 69 & 18.2 \\
\hline Traditionalist & 13 & 3.4 \\
\hline Other & 25 & 6.6 \\
\hline \multicolumn{3}{|l|}{ Occupation } \\
\hline Sex work & 102 & 26.8 \\
\hline Small business & 75 & 19.7 \\
\hline Salaried employee & 95 & 25 \\
\hline Student & 65 & 17.1 \\
\hline Casual labourer & 43 & 11.3 \\
\hline \multicolumn{3}{|c|}{$\begin{array}{l}\text { Whether cohabiting with male or female } \\
\text { partner }\end{array}$} \\
\hline Married to a female partner & 79 & 20.8 \\
\hline Living with male sexual partner & 68 & 17.9 \\
\hline Married but living alone & 33 & 8.7 \\
\hline Not married & 200 & 52.6 \\
\hline \multicolumn{3}{|l|}{ Ever using alcohol in the last 4 weeks } \\
\hline Every day & 95 & 25.0 \\
\hline Once a week & 184 & 48.4 \\
\hline$<1$ week & 53 & 13.9 \\
\hline Never & 48 & 12.6 \\
\hline \multicolumn{3}{|l|}{ Ever using drugs } \\
\hline Khat & 107 & 28.2 \\
\hline Bhang & 137 & 36.1 \\
\hline Glue, petrol & 11 & 2.9 \\
\hline Cocaine & 33 & 8.7 \\
\hline Heroin & 14 & 3.7 \\
\hline All & 11 & 2.9 \\
\hline None & 67 & 17.6 \\
\hline
\end{tabular}

related to factors that affected accessibility to HIV/AIDS prevention services by the MSM, acceptability of the same
TABLE 2: Accessibility to HIV/AIDS prevention services among MSM.

\begin{tabular}{|c|c|c|}
\hline Variable & $n=380$ & $\%$ \\
\hline \multicolumn{3}{|c|}{ Accessibility to condoms when needed } \\
\hline Yes & 321 & 84.5 \\
\hline No & 42 & 11.1 \\
\hline I do not use & 17 & 4.5 \\
\hline \multicolumn{3}{|c|}{$\begin{array}{l}\text { Availability of circumcision services in area } \\
\text { of operation or residence }\end{array}$} \\
\hline Yes & 270 & 71.1 \\
\hline No & 40 & 10.5 \\
\hline I do not know & 70 & 18.4 \\
\hline \multicolumn{3}{|c|}{ TB drugs easily accessible } \\
\hline Yes & 268 & 70.5 \\
\hline No & 45 & 11.8 \\
\hline I do not know & 67 & 17.6 \\
\hline \multicolumn{3}{|c|}{ Antiretroviral easily accessible } \\
\hline Yes & 272 & 71.6 \\
\hline No & 48 & 12.6 \\
\hline I do not know & 60 & 15.8 \\
\hline \multicolumn{3}{|c|}{ Accessibility to lubricants when needed } \\
\hline Yes & 302 & 79.5 \\
\hline No & 62 & 16.3 \\
\hline I do not know & 16 & 4.2 \\
\hline \multicolumn{3}{|c|}{ Access to IEC materials on HIV/AIDS } \\
\hline Yes & 269 & 70.8 \\
\hline No & 111 & 29.2 \\
\hline \multicolumn{3}{|c|}{ Access to training in HIV/AIDS } \\
\hline Yes & 261 & 68.7 \\
\hline No & 119 & 31.3 \\
\hline \multicolumn{3}{|c|}{$\begin{array}{l}\text { Accessibility to health facilities when } \\
\text { required to see a doctor }\end{array}$} \\
\hline Yes & 274 & 72.1 \\
\hline No & 106 & 27.9 \\
\hline \multicolumn{3}{|c|}{ Accessibility to treatment for STIs } \\
\hline Yes & 292 & 76.8 \\
\hline No & 47 & 12.4 \\
\hline I do not know & 41 & 10.8 \\
\hline
\end{tabular}

services, adherence to the services provided, and any challenges encountered at facility level while seeking health services by the MSM.

4.2.1. Accessibility. The study investigated the extent to which discrimination, the level of social stigma, attitude of health workers, violation of human rights, and confidentiality of patients' diagnosis had a bearing on HIV/AIDS health service provision and their implications. In the quantitative study, discrimination accounted for $31.6 \%$ of possible impediments to accessibility and when combined with social stigma over half of the respondents, 53.2\%, attributed inaccessibility to these two factors with stigma accounting for $26.3 \%$. 


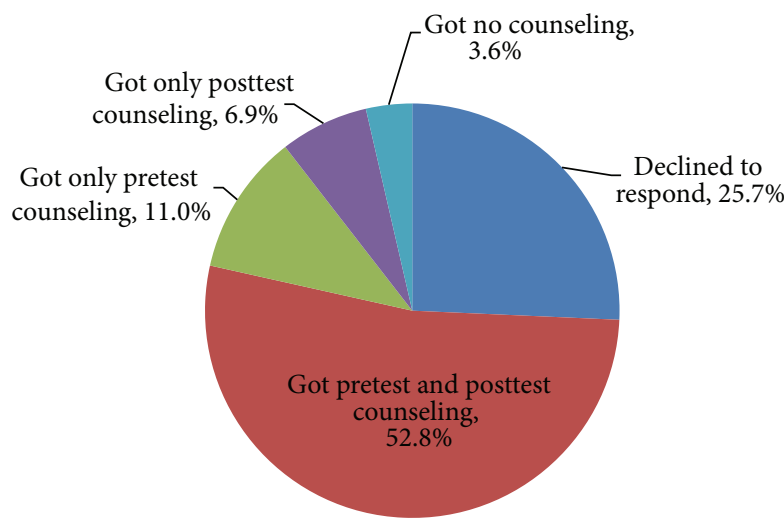

FIGURE 2: Counseling among those who had undertaken HIV test prior to the study.

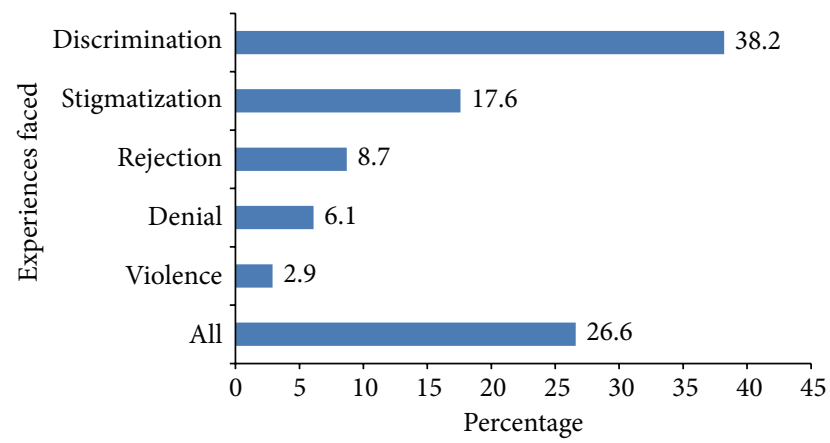

Figure 3: Experiences faced in their daily interaction as MSM.

The majority of the respondents who said they could visit any health facility for medical attention actually visited private clinics instead of public hospitals and attributed this tendency to relatively better services offered provided the service had been paid for. Those who had visited public health facilities complained of what they termed unfriendly health staff.

\begin{abstract}
I had a health problem, an anal wart and then I went to a public health facility. After the nurse realized I was gay, she called other nurses, laughing, to come and see, like a movie, like drama, Even in hospitals, a nurse told me to go for prayer otherwise I will go to hell, the nurses just gossip about us and you are on the line waiting we feel very bad. (MSM participant)
\end{abstract}

Some of the MSM reported during interviews that they did not attend public health facilities unless they had been referred to them, preferring to be discrete about their networks and activities. They reported being kept in long queues while other patients were being attended to including those who had arrived after them, as reported by one participant.

There was a time we were called to go to a referral hospital for a training and we were treated very well and told that our health issues would be treated differently. But that was not the case because when I visited for treatment, I was told to go to casualty area and pay, the queue was so long and I was in pain, I just left. Actually I learned that they operated on two MSM that had anal warts and the doctors told them that they were tired. We ceased going there, now we go to County hospital;. You see, cases of anal warts are very high and there is fear of disclosure so many go unreported and people just die. Sometimes they are presented late. We see these cases in MSM friendly organizations but they do not have the capacity to handle this and private health facilities are expensive. (MSM participant)

Social stigma was considered by the respondents as the second-most-serious barrier to accessing health facilities. They experienced social stigma from health workers in the public health facilities that some of them visited on referral.

The challenge is that these people (MSM) are marginalized and they fear seeking health care in facilities because of stigma and the law because legally they are not accepted within our society. But they find private facilities more friend$l y$ because the services are paid for. (KI from public health facility)

4.2.2. Acceptability. In this study, it was established that NGOs offered health services to about 13,000 MSM in Nairobi County. The MSM had registered with them for treatment and psychosocial support.

Some NGOs involved in health service delivery for the MSM relied on foreign donor funding and, after donor withdrawal or reduced funding level, the MSM went without essential health services such as screening for other STIs, hepatitis, HIV/AIDS, and psychosocial support and provision of condoms and lubricants.
At (facility X) which was funded by APHIA+, we had an MSM stationed there as a focal person for MSM health issues. There you could go and be treated very well, given all the medication, con- doms and lubricants but when APHIA+ left, the programme died, we no longer go there because even the nurses changed their attitude towards us. (MSM participant)

It was reported that while some NGOs handled over 13,000 MSM, the Nairobi County health facilities that we visited reported to have handled up to 2,222 MSM patients. These NGOs worked also in consultation with public health institutions some of whose health workers were reported to have lacked medical ethical conduct and also needed enhanced training in handling MSM health challenges. The county government was aware of these challenges and was working with the national government to minimize the challenges to enhance acceptability by MSM population but still on a small scale.

The county health sector has realized the need to scale-up the uptake of HIV/AIDS preventive measures among this MSM population. 
What the county has done with the support of the national government is to sensitize the health workers how to deal with MSM because health workers are also stigmatized, most of them have not dealt with MSM. There are also some facilities which keep a friendly atmosphere. (Nairobi County health director)

However, on the ground, in the six county health facilities visited, only one facility had a comprehensive healthcare programme that was friendly to the specific health needs of MSM.

4.2.3. Adherence. Intervention strategies to support adherence to HIV/AIDS prevention services have been found to be important in the achievement of positive outcomes [17]. The services available and for which strict adherence was required included strict utilization of antiretroviral medicines, utilization of condoms and lubricants, tuberculosis drugs meant for those infected, and diagnosis and treatment of anal sex related complications. The study established that MSM were likely to engage in unprotected anal sex with clients in return for a higher degree of pleasure and more money.

For me I use condom on women and not with men. Condom use reduces pleasure. Pleasure and money are more important so the risks of not using protection are an afterthought. (MSM participant)

Some of the MSM often interrupted their psychosocial support and treatment in NGO establishments by disappearing for a while only to reappear with advanced anal disorders such as warts, anal discharges, and other health complications, as reported by a key informant.

Some of them are hard-core. They don't want to be told and even if you schedule them for follow-up clinic they will not come and will come later when they develop problems. Some even come when they have stopped taking medicine. Adherence to treatment is a big challenge for us. (KII from a nongovernmental organization)

Others took partial screening tests and did not come for subsequent ones including pre- and posttreatment counseling. This is in agreement with the quantitative data, where only $11 \%$ of the MSM reported that they had gone for pretest counseling for HIV and never returned for posttest, and only $6.9 \%$ went for posttest, while $3.6 \%$ never went for any counseling sessions while $25 \%$ did not respond to the question on counseling.

They further absented themselves from the NGO support institutions when they had appointments. They did not adhere to medical prescriptions where required and some did not purchase the prescribed medicines, a factor that often affected their treatment durations and regimen. Others were reported not to adhere to the prescriptions due to the influence of alcohol and drugs. A KI from one NGO that provides HIV/AIDS prevention services to MSM presented challenges as follows.

\begin{abstract}
Challenges are numerous: it is sometimes difficult to make a follow up because MSM disappear for a while only to come back when having health issues. Most of them take alcohol and drugs which make them forget to take their medication for those who are positive. Most of them are unwilling to visit government hospitals when faced with a health challenge because of their identity they fear being noticed and therefore stigmatized. Some of them are not willing to utilize VCT services as often as is required. Another case we have seen is that of peer pressure whereby non-positives quickly become positive to belong. (key informant from NGO)
\end{abstract}

\section{Discussion}

The study investigated access to HIV prevention services in health facilities by MSM and the challenges encountered. Discrimination, social stigma, and the negative attitude of health workers were the main factors that adversely affected access to HIV/AIDS health service provision in the health facilities. Going through the litereature, some studies cited reproductive pressure, hostile attitudes, and denouncements from the political and religious class and overall social exclusion as impediments faced by MSM in terms of healthcare seeking [18]. Other studies [19] have reported additional factors affecting accessibility to health services for MSM that include fear of needles and lack of awareness of venues that provided HIV/AIDS testing venues. In other studies, inaccessibility was associated with fear of testing positive and perceiving no risk for HIV [20]. In this study, however, due to discrimination and stigma, the majority of the respondents who said they could visit any health facility for medical attention actually preferred private clinics instead of public hospitals because they provided better services if one could afford to pay for them. Some of the MSM reported during interviews that they did not attend public health facilities unless they had been referred to them, preferring to be discrete about their networks and activities. They reported being discriminated against in the facilities, including being kept in long queues while other patients, some who had come after them, were attended to.

This evidence of discrimination is in total disregard of Section 5.1.1 of the National Kenya Health Policy, 2012-2030. It was noted that the Nairobi County health policy has not been drafted. The 2012-2030 health policy gives directions to ensure significant improvement in overall status of health in Kenya in line with the country's long-term development agenda, Vision 2030, the Constitution of Kenya 2010 and global commitments. The HIV Prevention and Control Act 2006 also protects the rights of HIV/AIDS infected and affected people and outlaws discrimination against persons living with HIV/AIDS or suspected of having HIV/AIDS. The MSM experienced social stigma mostly from health workers in public hospitals that some of them visited on referral. Although their sexual orientation remained guarded, disclosure of their status as MSM by some of them elicited unanticipated resentment among health workers, especially 
nurses who derided them by calling other nurses to witness their anal warts during examination and thereafter laughed and engaged in gossip as the MSM left the health facilities. MSM social interactions with health providers needed to be improved so that the MSM and the health providers could take one another in confidence in matters of personfocused treatment and care. What is needed is sensitization of the health workers to provide healthcare services equally.

The occupation of the MSM in this study contrasted sharply with what Dowsett et al. [21] found after reviewing study reports on MSM social networks and behavior in India, Malaysia, Indonesia, and Thailand. The MSM in some of these countries had substantive income earning from diverse occupations of fishermen, factory workers, truck drivers, and military recruits. But in this study the MSM were mainly students, casual labourers, small businessmen, sex workers, and a few salaried employees. They generally belonged to low income groups. This means they could hardly meet treatment costs in private facilities. With accessibility already constrained by the above factors, acceptability of service depended on availability of facilities and how HIV/AIDS medical services were regulated and organized. It is also critical to note that preventive interventions have mainly focused on the proximal causes of HIV infection, that is, sexual behavior. However, structural factors also drive HIV transmission, majorly through marginalization of at-risk populations that limits access to treatment and prevention resources and also by shaping the general socioenvironmental context in which HIV risk and preventive practices are produced as alluded in other studies [22-25]. Structural interventions that work by altering the context in which health is produced and reproduced have a bearing on public health and typically involve regulatory, funding, and other policystyle mechanisms to enhance the availability, acceptability, and accessibility of preventive services [26].

On adherence, the study established that the MSM engaged in unprotected anal sex with clients in return for experiencing a high level of pleasure and earning more money, despite the advice from the health workers that they should not engage in unprotected sex. Relatively high rates of alcohol consumption and drug use also contributed to nonadherence to safe sex and treatment prescriptions. Apart from alcohol, some abused drugs such as bhang, khat, cocaine, heroin, glue, and petrol. They sometimes interrupted their psychosocial support and treatment in NGO establishments by disappearing for a while only to reappear with health complications. The MSM absented themselves from the NGO service providers without taking medical prescriptions where required and buying the prescribed medicines, a factor that often affected their treatment durations and regimen. The identification of these factors confirmed a similar finding on heterosexuals in other studies [27] that concluded that individuals who engaged in heterosexual anal sex were more likely to engage in other risk behaviors such as unprotected sex, alcohol and substance use, and trading sex. Peer group counselors through outreach strategies should therefore continue to engage with MSM so as to address some of these challenges.

\section{Conclusion}

The majority of the MSM (about 70\%) were able to access the basic HIV and AIDS prevention services in health facilities in Nairobi County including drugs, lubricants, and condoms. However, only about half accessed both pre- and postcounseling services for HIV and AIDS. The main factors adversely affecting access to the services were discrimination and stigmatization, particularly from health workers in the facilities.

\section{Additional Points}

The study focused on a special group of people classified as Most At-Risk Persons in social study terms. Snowballing was used to recruit respondents for the quantitative data while purposive sampling was used to recruit participants for qualitative data and therefore results obtained from these sampling combinations cannot be generalized. Besides, the study took place only in one out of forty-seven counties in Kenya and resultant data cannot be regarded as representing national data. Self-reported information about the sexual behavior and service uptake may lead to recall bias. Secondly, the quantitative data collection was carried out using a selfadministered questionnaire and therefore some behaviors might have been underreported or overreported. Despite these limitations, we believe that the present study generated valuable information to enhance the effectiveness of HIV prevention programmes among the MSM community.

\section{Competing Interests}

The authors declare that they have no competing interests.

\section{Authors' Contributions}

P. C. N. Otambo was involved in conceptualizing the objective of this paper, analyzing the data, interpreting the findings, literature search, and writing of the paper. A. Makokha, M. Karama, and M. Mwangi were involved in interpretations of the findings and extensive revisions of the paper.

\section{Acknowledgments}

Appreciation goes to KEMRI management for sponsoring this project through the KEMRI Internal Research Grant no. IRG/119/4. The authors wish to thank the Nairobi County Health Director for allowing this study to be carried out in the selected health facilities. The participation of the MSM community is highly appreciated.

\section{References}

[1] UNAIDS, The Gap Report, 2014, http://www.unaids.org/.

[2] E. J. Sanders, S. M. Graham, H. S. Okuku et al., "HIV-1 infection in high risk men who have sex with men in Mombasa, Kenya," AIDS, vol. 21, no. 18, pp. 2513-2520, 2007.

[3] S. Geibel, J. Okal, W. Tun, M. Sheehy, D. Broz, and H. Mutua, "HIV and STI prevalence among men who have sex with men in Nairobi: results from a respondent-driven sampling 
study," in Proceedings of the 1st National Biennial HIV and AIDS Conference (NACC '11), Abstract no. D028, Nairobi, Kenya, May 2011.

[4] S. Baral, F. Sifakis, F. Cleghorn, and C. Beyrer, "Elevated risk for HIV infection among men who have sex with men in lowand middle-income countries 2000-2006: a systematic review," PLoS Medicine, vol. 4, no. 12, article e339, 2007.

[5] A. S. Wade, J. Larmarange, A. K. Diop, O. Diop, K. Gueye, and A. Marra, "Reduction in risk-taking behaviors among MSM in Senegal between 2004 and 2007 and prevalence of HIV and other STIs," AIDS Care, vol. 22, no. 4, pp. 409-414, 2010.

[6] B. Vuylsteke, G. Semde, L. Sika et al., "High prevalence of HIV and sexually transmitted infections among male sex workers in Abidjan, Côte d'Ivoire: need for services tailored to their needs," Sexually Transmitted Infections, vol. 88, no. 4, pp. 288-293, 2012.

[7] S. Baral, F. Sifakis, F. Cleghorn, and C. Beyrer, "Elevated risk for HIV infection among men who have sex with men in lowand middle-income countries 2000-2006: a systematic review," PLoS Medicine, vol. 4, no. 12, pp. 1901-1911, 2007.

[8] UNAIDS, The Gap Report, 2014.

[9] G. Ayala, K. Makofane, G.-M. Santos et al., "Access to basic HIVRelated services and PrEP acceptability among men who have sex with men worldwide: barriers, facilitators, and implications for combination prevention," Journal of Sexually Transmitted Diseases, vol. 2013, Article ID 953123, 11 pages, 2013.

[10] C. F. Cáceres, K. Konda, E. R. Segura, and R. Lyerla, "Epidemiology of male same-sex behaviour and associated sexual health indicators in low- and middle-income countries: 2003-2007 Estimates," Sexually Transmitted Infections, vol. 84, no. 1, pp. 4956, 2009.

[11] M. Amadou, P. Tapsoba, A. Ly, C. I. Niang, and A. K. Diop, Implementing STI/HIV Prevention and Care Interventions for Men Who Have Sex with Men in Senegal. Horizons Study Summary, Population Council, Washington, DC, USA, 2007.

[12] A. Bourne, "Drug use among men who have sex with men: implications for harm reduction," in Global State of Harm Reduction 2012, C. Stoicescu, Ed., pp. 147-155, Harm Reduction International, London, UK, 2012.

[13] C. Cáceres, K. Konda, E. Segura, and R. Lyerla, "Epidemiology of male same-sex behaviour and associated health indicators in low- and middle-income countries: 2003-2007 estimates," Sexually Transmitted Infections, vol. 84, pp. 49-56, 2003.

[14] A. J. Onwuegbuzie and N. L. Leech, "Enhancing the interpretation of, 'significant', findings: the role of mixed methods research," The Qualitative Report, vol. 9, pp. 770-792, 2004.

[15] J. W. Creswell, V. L. Plano Clark, M. Gutmann, and W. Hanson, "Advanced mixed methods research designs," in Handbook of Mixed Methods in Social and Behavioral Research, A. Tashakkori and C. Teddlie, Eds., pp. 209-240, Sage, Thousand Oaks, Calif, USA, 2003.

[16] J. Saldaña, The Coding Manual for Qualitative Researchers, Sage, London, UK, 2009.

[17] K. R. Amico, J. J. Harman, and B. T. Johnson, "Efficacy of antiretroviral therapy adherence interventions: a research synthesis of trials, 1996 to 2004," Journal of Acquired Immune Deficiency Syndromes, vol. 41, no. 3, pp. 285-297, 2006.

[18] A. D. Smith, P. Tapsoba, N. Peshu, E. J. Sanders, and H. W. Jaffe, "Men who have sex with men and HIV/AIDS in sub-Saharan Africa," The Lancet, vol. 374, no. 9687, pp. 416-422, 2009.

[19] D. Huang, Y. Hu, G. Wu et al., "HIV prevention services and testing utilization behaviors among men who have sex with men at elevated risk for HIV in Chongqing, China," BioMed Research International, vol. 2014, Article ID 174870, 10 pages, 2014.

[20] Y. Zhao, L. Zhang, H. Zhang et al., "HIV testing and preventive services accessibility among men who have sex with men at high risk of HIV infection in Beijing, China," Medicine, vol. 94, no. 6, article e534, 2015.

[21] G. Dowsett, J. Grierson, and S. MacNally, Review of Knowledge about the Sexual Networks and Behaviour of Men Who Have Sex with Men in Asia. September 2003, Monograph Series No. 59, Australian Study Centre in Sex, Health and Society, La Trop University, Melbourne, Australia, 2006.

[22] R. G. Parker, D. Easton, and C. H. Klein, "Structural barriers and facilitators in HIV prevention: a review of international research," AIDS, vol. 14, no. 11, pp. S22-S32, 2000.

[23] T. Rhodes, M. Singer, P. Bourgois, S. R. Friedman, and S. A. Strathdee, "The social structural production of HIV risk among injecting drug users," Social Science and Medicine, vol. 61, no. 5, pp. 1026-1044, 2005.

[24] E. Sumartojo, "Structural factors in HIV prevention: concepts, examples, and implications for research," AIDS, vol. 14, no. 11, pp. S3-S10, 2000.

[25] C. Beyrer, S. D. Baral, F. Van Griensven et al., "Global epidemiology of HIV infection in men who have sex with men," The Lancet, vol. 380, no. 9839, pp. 367-377, 2012.

[26] K. M. Blankenship, S. J. Bray, and M. H. Merson, "Structural interventions in public health," AIDS, vol. 14, supplement 1, pp. S11-S21, 2000.

[27] Z. Duby and C. Colvin, "Conceptualizations of heterosexual anal sex and HIV risk in five east African communities," Journal of Sex Research, vol. 51, no. 8, pp. 863-873, 2014. 


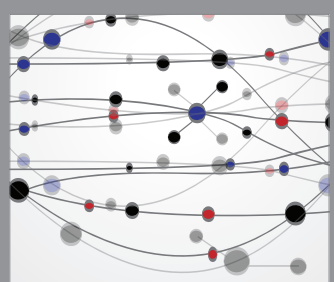

The Scientific World Journal
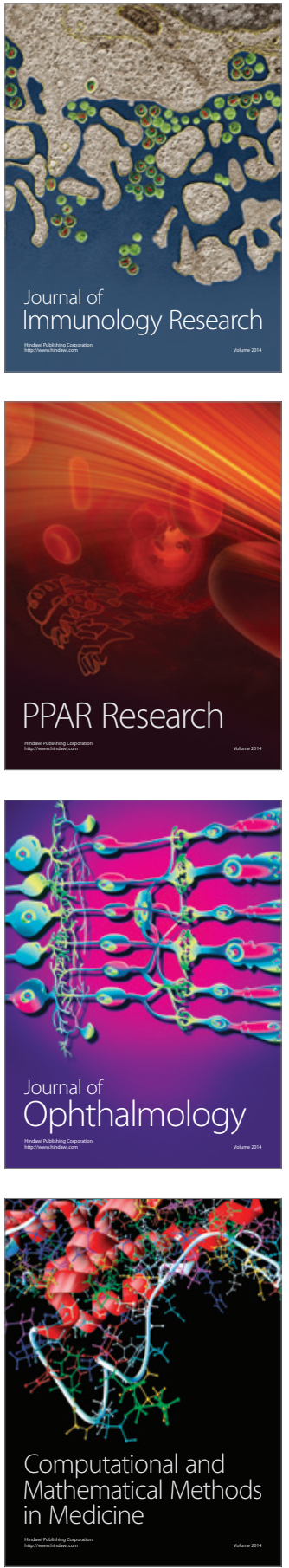

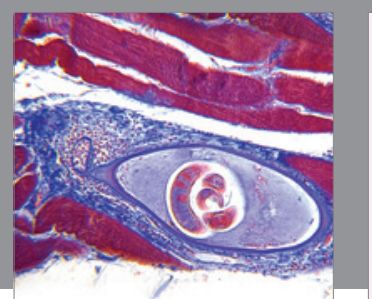

Gastroenterology Research and Practice

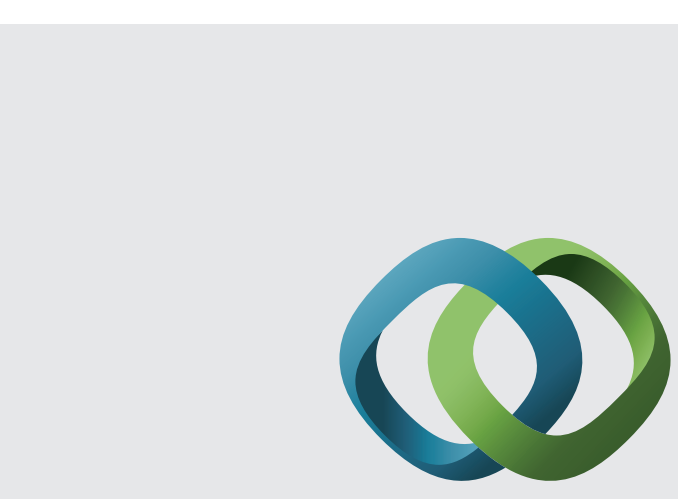

\section{Hindawi}

Submit your manuscripts at

http://www.hindawi.com
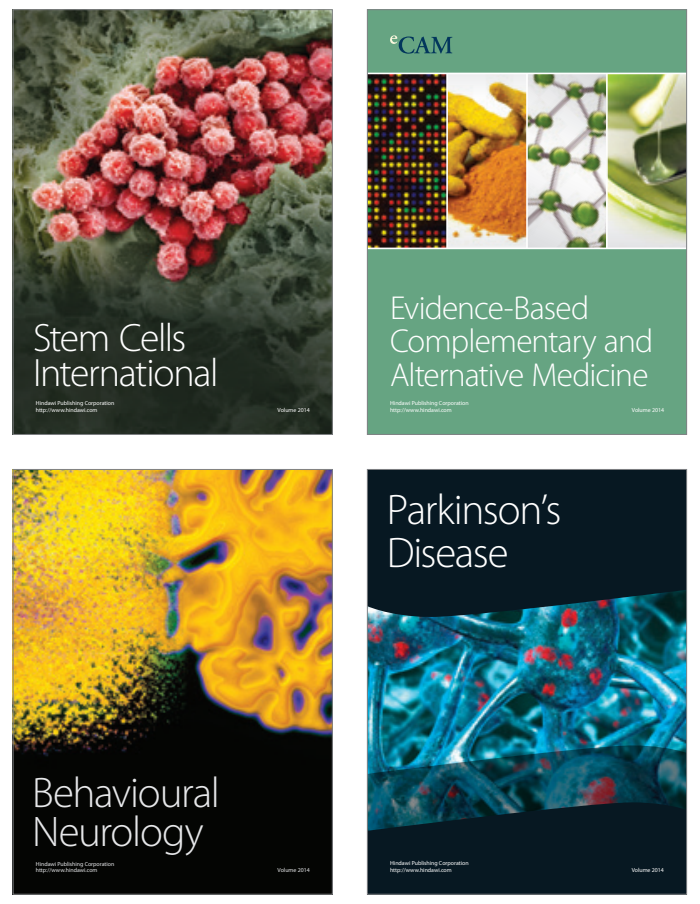
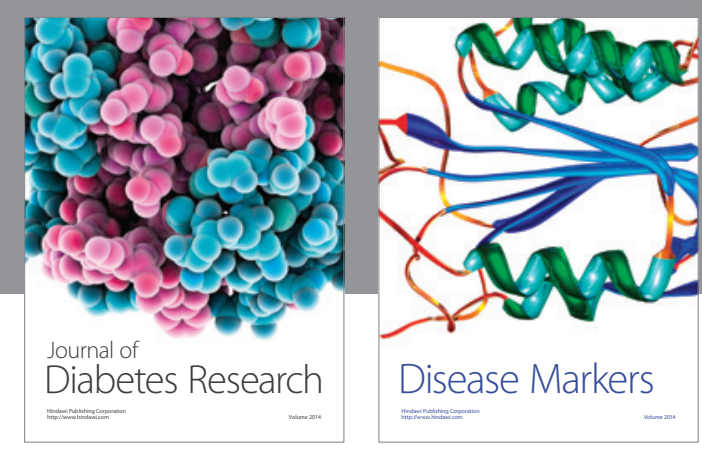

Disease Markers
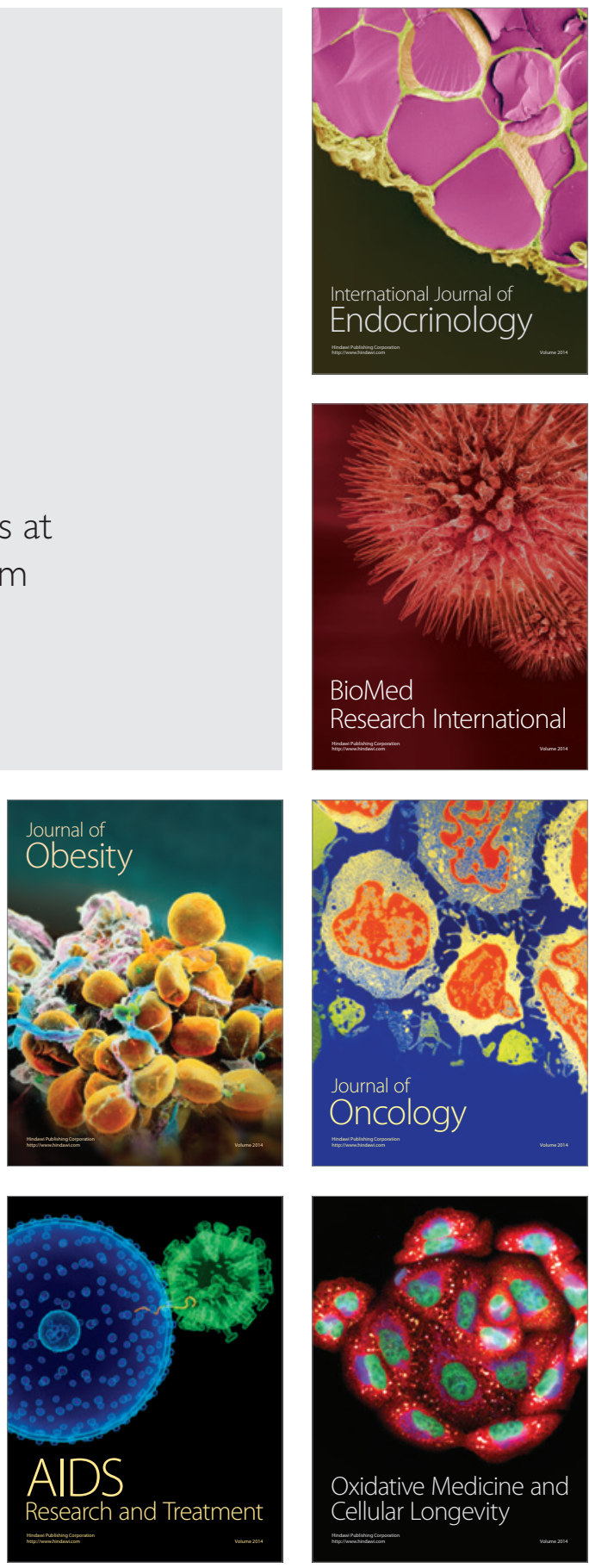